\title{
Reverse fluorescein cap sign of cavernous haemangioma of optic nerve on OCT angiography
}

\author{
Padmaja Kumari Rani, ${ }^{1}$ Hari Kumar Peguda, ${ }^{1}$ Swathi Kaliki, ${ }^{1}$ Jay Chhablani ${ }^{2}$
}

'LV Prasad Eye Institute, Hyderabad, Andhra Pradesh, India

${ }^{2}$ Department of Vitreo-Retina, LV Prasad Eye Institute, Hyderabad, Andhra Pradesh, India

Correspondence to Dr Padmaja Kumari Rani, rpk111@gmail.com

Accepted 20 October 2016
CrossMark

\section{To cite: Rani PK,}

Peguda HK, Kaliki S, et al. $B M J$ Case Rep Published

online: [please include Day

Month Year] doi:10.1136/

bcr-2016-218176

\section{DESCRIPTION}

A man aged 57 years, a known hypertensive, presented with symptoms of visual loss in the upper field in the left eye since 6 months. Best-corrected visual acuity in both eyes was 20/20, N6 (with eccentric fixation in the left eye). On clinical examination, he was found to have a vascular malformation of the optic nerve head $(\mathrm{ONH})$ with typical grape clusters appearance of $\mathrm{ONH}$ in both eyes, suggestive of cavernous haemangioma and associated inferotemporal branch retinal artery occlusion corresponding to the upper visual field defect in the left eye.

Cavernous haemangioma is a non-progressive rare retinal vascular hamartoma. Typical fundus findings are clumps of dark saccular aneurysms (cluster of grapes appearance) with fibroglial tissue over the tumour, absence of feeder vessels and absence of exudation. Complications include haemorrhage and retinal arterial occlusions. ${ }^{1}{ }^{2}$ Diagnosis is based on clinical picture and typical fluorescein cap sign seen on fundus fluorescein angiography (FFA) due to hyperfluorescence due to staining of supernatant plasma and hypofluorescence at the bottom of the aneurysm.

FFA typically showed fluorescein caps due to staining of supernatant plasma in the vascular malformations of $\mathrm{ONH}$ (figure 1A). We observed a 'reverse fluorescein cap sign' with echolucent space in the area of plasma superiorly and bright signal due to blood flow at the bottom of aneurysm detected on optical coherence tomography (OCT) angiography of ONH (figure 1B) clinching the diagnosis of cavernous haemangioma of

\section{Learning points}

A typical fluorescein cap sign of retinal vascular malformation seen on fundus fluorescein angiography (invasive imaging) clinches the confirmatory diagnosis of cavernous haemangioma.

- Optical coherence tomography angiography is a promising non-invasive imaging technique that confirms the diagnosis of cavernous haemangioma by showing a typical reverse fluorescein cap sign.

ONH. OCT angiography can be used as a noninvasive tool in the diagnosis of cavernous haemangioma of $\mathrm{ONH}$.

\section{Contributors PKR is responsible for concept, design and} preparation and editing of manuscript. HKP is responsible for collection of data, preparation and editing of manuscript. SK is responsible for design and preparation and editing of manuscript. JC is responsible for design and preparation and editing of manuscript.

Competing interests None declared.

Patient consent Obtained.

Provenance and peer review Not commissioned; externally peer reviewed.

\section{REFERENCES}

1 Sacconi R, Giordano Resti A, Lattanzio R, et al. A case of branch retinal artery occlusion following orbital cavernous hemangioma excision. Eur J Ophthalmol 2014;24:972-5.

2 Grob SR, Campbell AA, Gross A, et al. Hemorrhage within the optic nerve from a cavernous hemangioma of the optic disc. J Neuroophthalmol 2015:35:277-9.
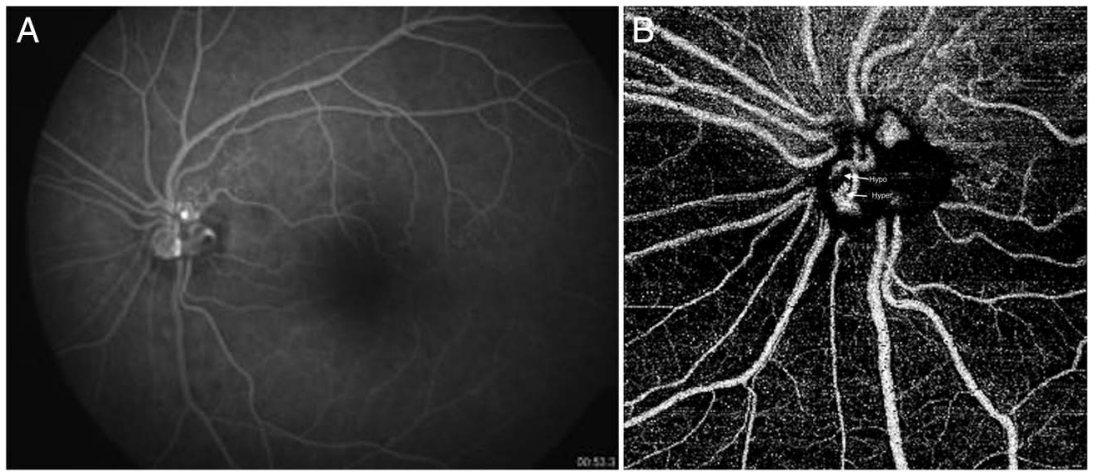

Figure 1 (A) Typical fluorescein cap due to staining of supernatant plasma on fundus fluorescein angiography and optical coherence tomography angiography shows reverse fluorescein cap sign with an echoluscent space superiorly and a bright signal at the bottom of aneurysm detecting the blood flow of the vascular malformation (B) in cavernous haemangioma of the optic nerve head. 
Copyright 2016 BMJ Publishing Group. All rights reserved. For permission to reuse any of this content visit http://group.bmj.com/group/rights-licensing/permissions.

BMJ Case Report Fellows may re-use this article for personal use and teaching without any further permission.

Become a Fellow of BMJ Case Reports today and you can:

- Submit as many cases as you like

- Enjoy fast sympathetic peer review and rapid publication of accepted articles

- Access all the published articles

- Re-use any of the published material for personal use and teaching without further permission

For information on Institutional Fellowships contact consortiasales@bmjgroup.com

Visit casereports.bmj.com for more articles like this and to become a Fellow 